\title{
Correction to: Calculation of a magnetic force acting on small superconducting celestial bodies
}

\section{Lukasz Tomkow ${ }^{\mathrm{a}}$ (D)}

Applied Superconductivity and Cryoscience Group, Department of Materials Science and Metallurgy, University of Cambridge, Cambridge CB3 OFS, UK

(C) The Author(s), under exclusive licence to Società Italiana di Fisica and Springer-Verlag GmbH Germany, part of Springer Nature 2021

Correction to: Eur. Phys. J. Plus (2021) 136:730 https://doi.org/10.1140/epjp/s13360-021-01703-6

The original version of this paper was inadvertently published with an incorrect affiliation. The correct affiliation is:

Applied Superconductivity and Cryoscience Group, Department of Materials Science and Metallurgy, University of Cambridge, Cambridge, CB3 OFS, UK.

The original article has been corrected. We apologise for any inconvenience caused to our readers.

The original article can be found online at https://doi.org/10.1140/epjp/s13360-021-01703-6.

\footnotetext{
a e-mail: lukasz.tomkow@ cern.ch (corresponding author)
} 